Article

\title{
Tuning Nano-Amorphous Calcium Phosphate Content in Novel Rechargeable Antibacterial Dental Sealant
}

\author{
Maria Salem Ibrahim ${ }^{1,2}$, Faisal D. AlQarni ${ }^{3}$, Yousif A. Al-Dulaijan ${ }^{3}$, Michael D. Weir ${ }^{4}$, \\ Thomas W. Oates ${ }^{4}$, Hockin H. K. Xu ${ }^{4,5,6}$ and Mary Anne S. Melo ${ }^{4, *}$ \\ 1 Program in Dental Biomedical Sciences, University of Maryland School of Dentistry, \\ Baltimore, MD 21201, USA; msyibrahim@gmail.com \\ 2 Department of Preventive Dental Sciences, College of Dentistry, Imam Abdulrahman bin Faisal University, \\ Dammam 34212, Saudi Arabia \\ 3 Department of Substitutive Dental Sciences, College of Dentistry, Imam Abdulrahman bin Faisal University, \\ Dammam 34212, Saudi Arabia; falqarni@icloud.com (F.D.A.); yaldulaijan@gmail.com (Y.A.A-D.) \\ 4 Department of Advanced Oral Sciences and Therapeutics, University of Maryland School of Dentistry, \\ Baltimore, MD 21201, USA; MWeir@umaryland.edu (M.D.W.); TOates@umaryland.edu (T.W.O.); \\ HXu@umaryland.edu (H.H.K.X.) \\ 5 Center for Stem Cell Biology \& Regenerative Medicine, University of Maryland School of Medicine, \\ Baltimore, MD 21201, USA \\ 6 Marlene and Stewart Greenebaum Cancer Center, University of Maryland School of Medicine, \\ Baltimore, MD 21201, USA \\ * Correspondence: mmelo@umaryland.edu; Tel.: +1-410-706-8705
}

Received: 19 July 2018; Accepted: 20 August 2018; Published: 27 August 2018

\begin{abstract}
Dental sealants with antibacterial and remineralizing properties are promising for caries prevention among children and adolescents. The application of nanotechnology and polymer development have enabled nanoparticles of amorphous calcium phosphate (NACP) and dimethylaminohexadecyl methacrylate (DMAHDM) to emerge as anti-caries strategies via resin-based dental materials. Our objectives in this study were to (1) incorporate different mass fractions of NACP into a parental rechargeable and antibacterial sealant; (2) investigate the effects on mechanical performance, and (3) assess how the variations in NACP concentration would affect the calcium $(\mathrm{Ca})$ and phosphate $\left(\mathrm{PO}_{4}\right)$ ion release and re-chargeability over time. NACP were synthesized using a spray-drying technique and incorporated at mass fractions of $0,10,20$ and $30 \%$. Flexural strength, flexural modulus, and flowability were assessed for mechanical and physical performance. $\mathrm{Ca}$ and $\mathrm{PO}_{4}$ ion release were measured over 70 days, and three ion recharging cycles were performed for re-chargeability. The impact of the loading percentage of NACP upon the sealant's performance was evaluated, and the optimized formulation was eventually selected. The experimental sealant at $20 \%$ NACP had flexural strength and flexural modulus of $79.5 \pm 8.4 \mathrm{MPa}$ and $4.2 \pm 0.4 \mathrm{GPa}$, respectively, while the flexural strength and flexural modulus of a commercial sealant control were $70.7 \pm 5.5 \mathrm{MPa}(p>0.05)$ and $3.3 \pm 0.5 \mathrm{GPa}(p<0.05)$, respectively. A significant reduction in flow was observed in the experimental sealant at $30 \% \mathrm{NACP}(p<0.05)$. Increasing the NACP mass fraction increased the ion release. The sealant formulation with NACP at $20 \%$ displayed desirable mechanical performance and ideal flow and handling properties, and also showed high levels of long-term Ca and $\mathrm{PO}_{4}$ ion release and excellent recharge capabilities. The findings provide fundamental data for the development of a new generation of antibacterial and rechargeable $\mathrm{Ca}$ and $\mathrm{PO}_{4}$ dental sealants to promote remineralization and inhibit caries.
\end{abstract}

Keywords: dental sealant; resin sealant; calcium phosphate nanoparticles; long-term ion release; remineralization; ion recharge 


\section{Introduction}

Dental caries is still a highly prevalent oral disease worldwide despite the various approaches that have been used to prevent it [1,2]. These approaches include fluoride exposure, sugar intake control, brushing and dental sealants [3]. Dental sealants help prevent caries in pits and fissures of primary and permanent teeth, acting as a physical barrier for food accumulation and bacterial growth [4]. Accumulative evidence from epidemiologic findings has shown positive outcomes for caries prevention when the teeth are sealed, in comparison to non-sealed teeth in children and adolescents $[4,5]$. It was found that sealants on permanent molars may reduce dental caries for up to 24-48 months when compared to that of no sealant application $[3,4]$. In terms of sealants' retention, resin-based sealants are the materials with a higher success rate [6]. Even so, findings have shown an increase in dental resin-based sealants failures due to bacterial colonization under the restored fissures, thereby, initiating and progressing the carious lesion beneath the sealant [4].

Caries lesions at the sealed occlusal surfaces were initiated when the balance between the remineralization and demineralization of the tooth structure was adversely affected, and demineralization exceeded the remineralization abilities, resulting in the dissolution of hydroxyapatite crystals [7]. To allow the remineralization process to occur, adequate levels of calcium (Ca) and phosphate $\left(\mathrm{PO}_{4}\right)$ ions must be available [8]. Antibacterial and remineralizing resin-based sealants could be one of the most desirable approaches for management of dental caries in children and adolescents due to the potential of reduced bacteria and provide localized ion release near the tooth surface.

Recently, new fundamental research findings have highlighted the application of nanotechnology and polymer development in dental materials, enabling nanoparticles of amorphous calcium phosphate (NACP) and quaternary ammonium methacrylate such as dimethylaminohexadecyl methacrylate (DMAHDM) to emerge as anti-caries strategies via resin-based materials $[9,10]$. Amorphous calcium phosphate $\left(\mathrm{Ca}_{3}\left[\mathrm{PO}_{4}\right]_{2}\right)$, as a precursor of the final crystalline hydroxyapatite, has been investigated as a suitable remineralizing agent. There is a growing body of evidence suggesting that NACP could enhance the remineralizing capacity due to a greater surface area-to-volume ratio [11,12]. NACP had a relatively high specific surface area of $17.76 \mathrm{~m}^{2} / \mathrm{g}$, compared to about $0.5 \mathrm{~m}^{2} / \mathrm{g}$ of traditional micron-sized calcium phosphate particles used in dental resins [13,14]. Supported by the high performance of $\mathrm{Ca}$ and $\mathrm{PO}_{4}$ ion release provided by a nanostructured compound, NACP has led to new possibilities for combating enamel demineralization [15].

Resin-based sealants with the ability to release $\mathrm{Ca}$ and $\mathrm{PO}_{4}$ ions are expected to suppress the demineralization process and prevent dental caries. However, ion-depletion effect with loss of bioactivity over time (short-term ion release) has been a major drawback for calcium phosphate-containing resins [6,16]. Recently, significant levels of $\mathrm{Ca}$ and $\mathrm{PO}_{4}$ ions were released from NACP-containing resins that were sustainable over long periods of time and with rechargeable capacity $[17,18]$. The rechargeable capability of NACP-containing dental materials have opened new horizons and are expected to lead to relevant changes in remineralizing approaches [19]. The repeatable recharge process to re-release $\mathrm{Ca}$ and $\mathrm{PO}_{4}$ ions can lead to supersaturation into the surrounding microenvironments under acidic attacks, such as enamel areas located within deep occlusal pits and fissures with difficult access to brush. These ions can play a vital role in the precipitation of crystallites. This capability is highly desirable in a resin-based formulation for sealing the occlusal pits and fissures where high rates of demineralization happen and result in almost $50 \%$ of all caries in school children [2,4].

Many of the innovative bioactive strategies and technologies require new dental materials with new combinations of properties to meet the basic properties of the conventional polymeric materials [13]. This is true for resin-based formulations that are needed for dental sealant applications. For example, regarding the chemical and physical characteristics, the resin-based sealants must possess 
a high degree of wettability, and flow and viscosity that allow the penetration between the occlusal fissures and grooves of the teeth [5]. Another important characteristic is the resistance to abrasion and fracture, which would demonstrate the adequate mechanical performance of the material [6]. This is a challenging combination of characteristics when developing new resin-based formulations. Frequently, the incorporation of new agents in the resin-based system decreases the strength or bioactivity.

The present study reports the development of new antibacterial resin-based sealants that include NACP for $\mathrm{Ca}$ and $\mathrm{PO}_{4}$ ion release and recharge properties. Our objectives were to (1) incorporate different mass fractions of NACP into parental rechargeable antibacterial sealant; (2) investigate the effects on mechanical performance; and (3) assess how the variations in NACP concentration would affect the $\mathrm{Ca}$ and $\mathrm{PO}_{4}$ ions release and re-chargeability over time. It was hypothesized that adding an increased percentage of NACP would have acceptable mechanical and physical performances, while producing substantial initial ion release and a long-term repeated recharge capability.

\section{Results}

Illustration of the rechargeable NACP approach to dealing with the dissolution-diffusion process of enamel demineralization around dental sealants is shown schematically in Figure 1. The ion recharge cycle diagram displayed the ion re-release from the exhausted and recharged NACP-containing resin-based sealants in Figure 1A. Three recharge/re-release cycles were performed, and each re-release was measured for 14 days. The ion re-release increased with increasing the NACP filler level. Figure 1B shows the TEM image of NACP synthesized using the spray-drying technique having sizes of about $100-300 \mathrm{~nm}$. The structural model of amorphous calcium phosphate is exemplified in this image, and the potential application for sealing the occlusal surface of the posterior teeth is illustrated.

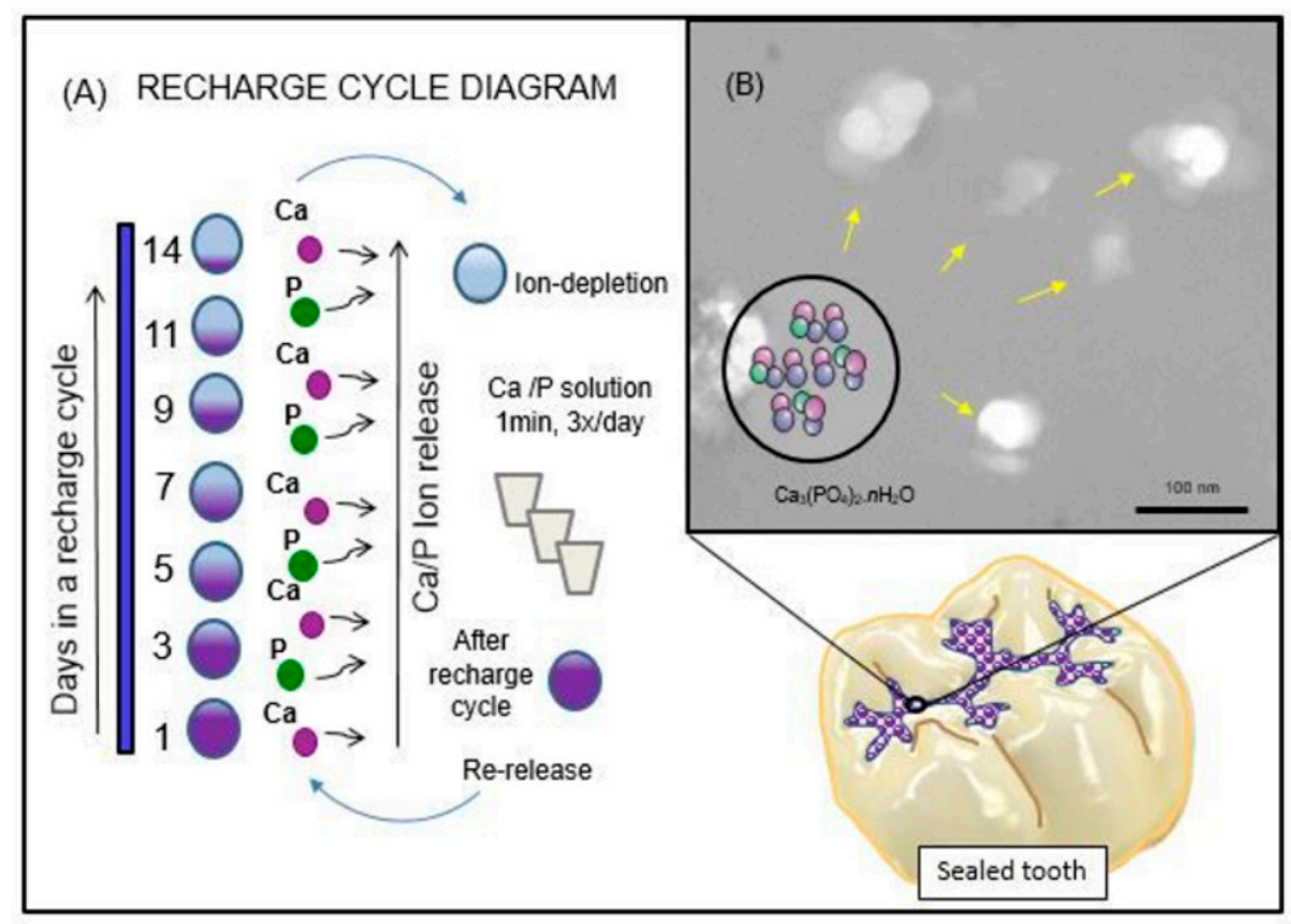

Figure 1. Schematic diagram of the rechargeable nanoparticles of amorphous calcium phosphate (NACP) sealant approach to deal with enamel demineralization around dental sealants: In (A), the recharge cycle diagram illustrates the re-release from the exhausted and recharged NACP sealants. Three recharge/re-release cycles were performed, and each re-release was measured for 14 days. The ion re-release increased with increasing the NACP filler level. In (B), the TEM image of NACP from the spray-drying technique having sizes of about 100-300 $\mathrm{nm}$. 
Figure 2 describes the flexural strength and modulus of the antibacterial and rechargeable resin-based sealants (Mean $\pm \mathrm{SD} ; n=8$ ). In Figure 2A, the flexural strength showed a decreasing trend with increasing NACP percentage, because the glass filler level was decreasing from $50 \%$ to $20 \%$. The experimental sealant at $20 \%$ NACP had the flexural strength and flexural modulus of $79.5 \pm 8.4 \mathrm{MPa}$ and $4.2 \pm 0.4 \mathrm{GPa}$, respectively. The commercial high viscosity sealant control showed flexural strength and flexural modulus of $70.7 \pm 5.5 \mathrm{MPa}(p>0.05)$ and $3.3 \pm 0.5 \mathrm{GPa}(p<0.05)$. These results demonstrated that the rechargeable antibacterial sealant at $20 \%$ mass fraction of NACP had mechanical properties similar to or higher than that of the commercial sealant/flowable composite control. Only the sealant with $30 \% \mathrm{NACP}$ had a significantly lower strength that those other groups $(p<0.05)$.

(A)

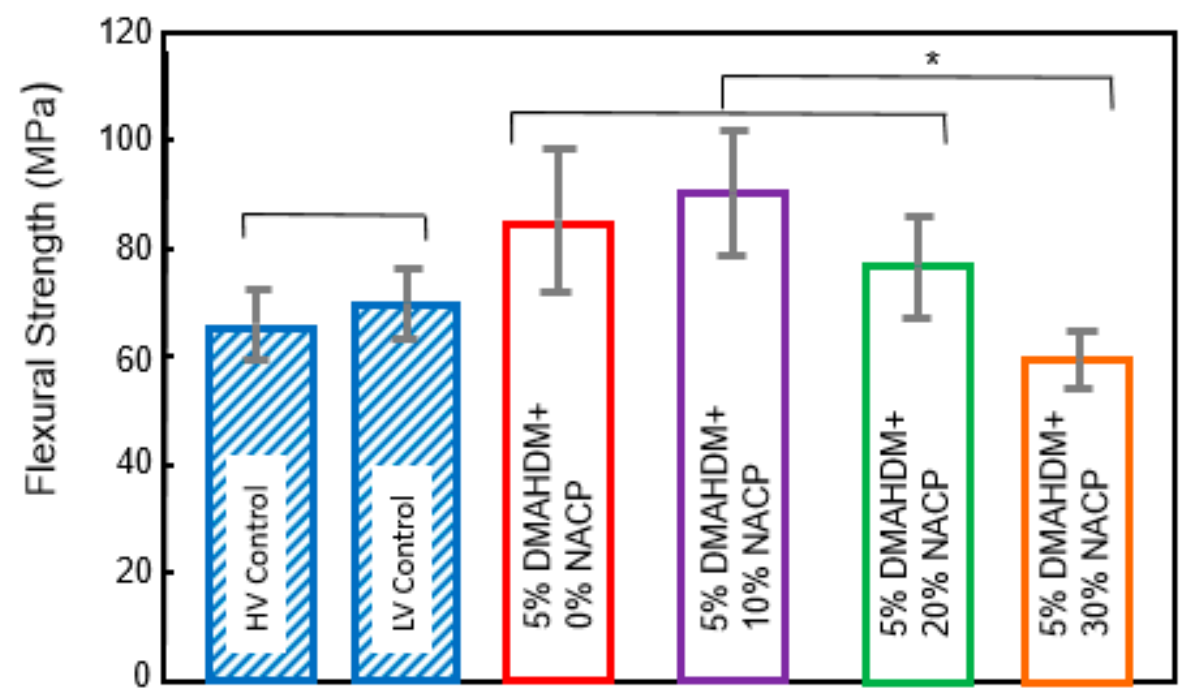

(B)

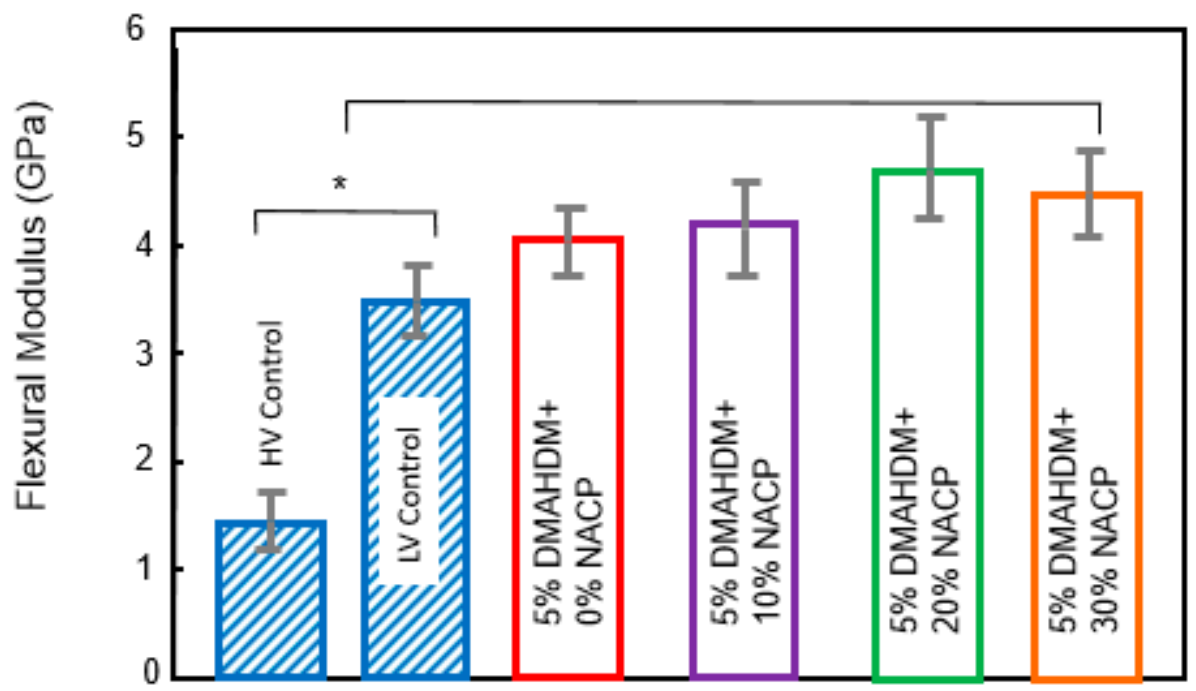

Figure 2. Bar graphs of (A) flexural strength and (B) flexural modulus (Mean $\pm \mathrm{SD} ; n=8$ ) of resin-based sealants. The asterisk means that there was a statistically significant difference between the groups. 
The flow results for the experimental and control resin-based sealants (Mean $\pm \mathrm{SD} ; n=6$ ) are plotted in Figure 3. NACP at a mass fraction of 30\% compromised the flow of the sealant $(p<0.05)$. Experimental sealant with a mass fraction of $20 \%$ NACP had a flow that was not significantly different from the control $(p>0.05)$.

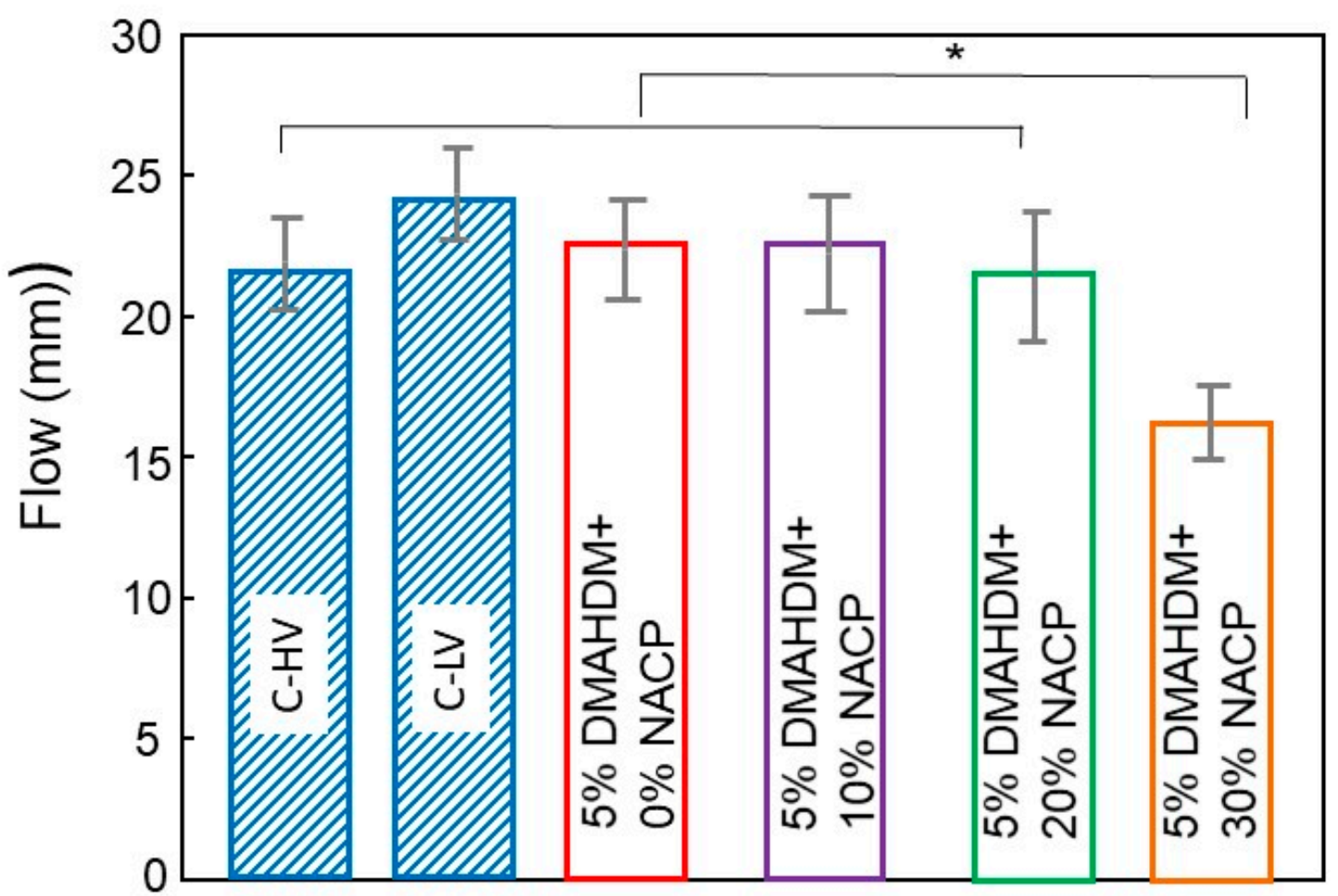

Figure 3. Means \pm SD of flow analysis of the resin-based sealant formulations $(n=6)$. The asterisk means that there was a statistically significant difference between the groups.

Figure 4 plots the $\mathrm{Ca}$ and $\mathrm{PO}_{4}$ initial ion release over time (Mean $\pm \mathrm{SD} ; n=6$ ). After 70 days of ion release, $30 \% \mathrm{NACP}+5 \%$ DMAHDM sealant had higher Ca ion release of $4.70 \pm 0.95 \mathrm{mmol} / \mathrm{L}$. This amount was significantly different from 20\% NACP + 5\% DMAHDM sealant that released $3.64 \pm 0.11 \mathrm{mmol} / \mathrm{L}(p<0.05)$. The $\mathrm{PO}_{4}$ ion release had similar release behavior. The $30 \% \mathrm{NACP}+$ $5 \%$ DMAHDM sealant showed $4.25 \pm 0.12 \mathrm{mmol} / \mathrm{L}$ of $\mathrm{PO}_{4}$ ion release, followed by the $20 \% \mathrm{NACP}$ $+5 \%$ DMAHDM with $3.41 \pm 0.10 \mathrm{mmol} / \mathrm{L}_{\text {of }} \mathrm{PO}_{4}$ ion release $(p<0.05)$. During the 70 days, the $\mathrm{pH}$ increased from approximately 4.5 to 6.5 for the groups of the formulations containing $20 \%$ and $30 \%$ NACP. These changes represent the neutralizing capabilities of calcium and phosphate ion release. 
(A)

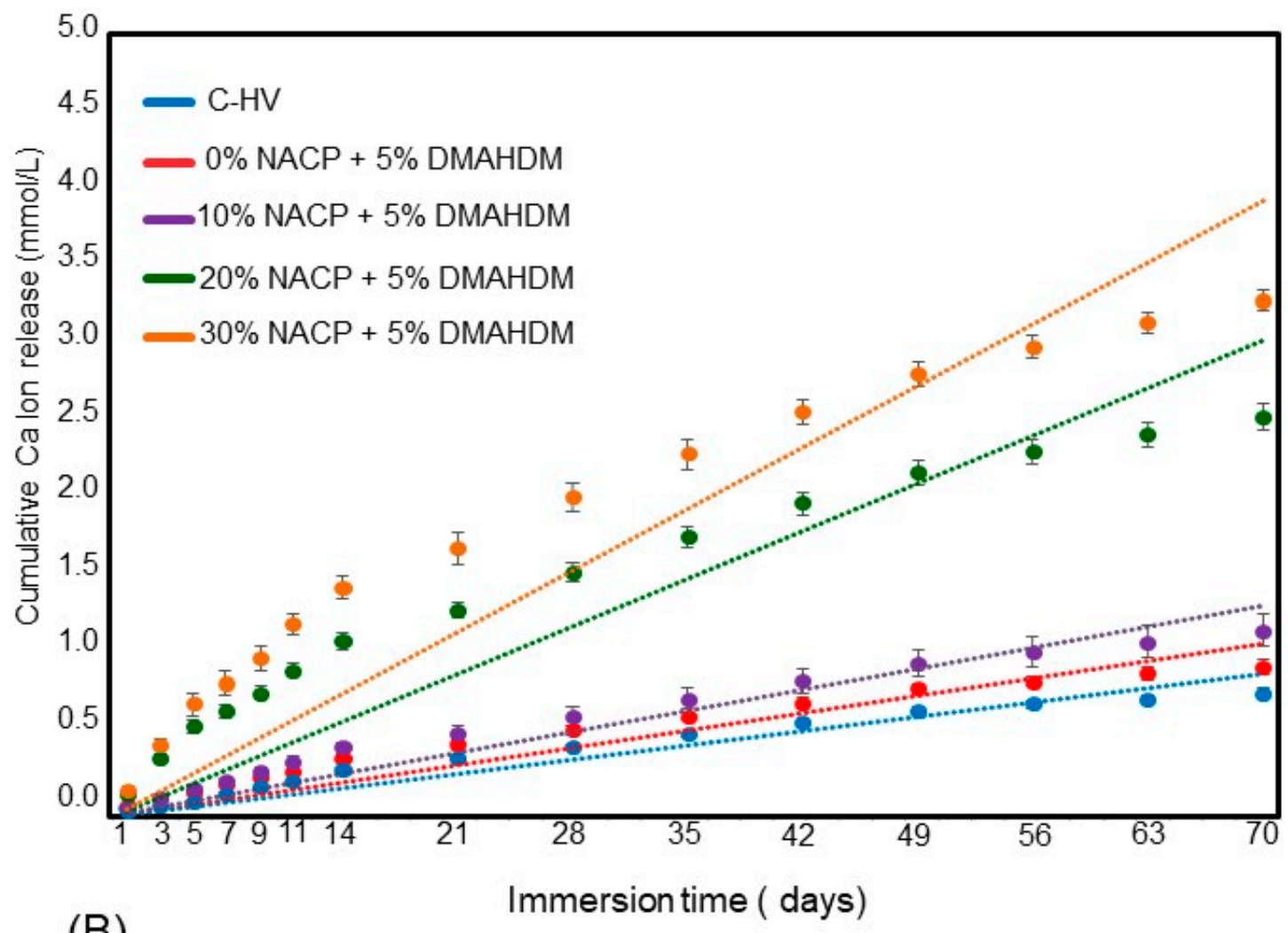

(B)

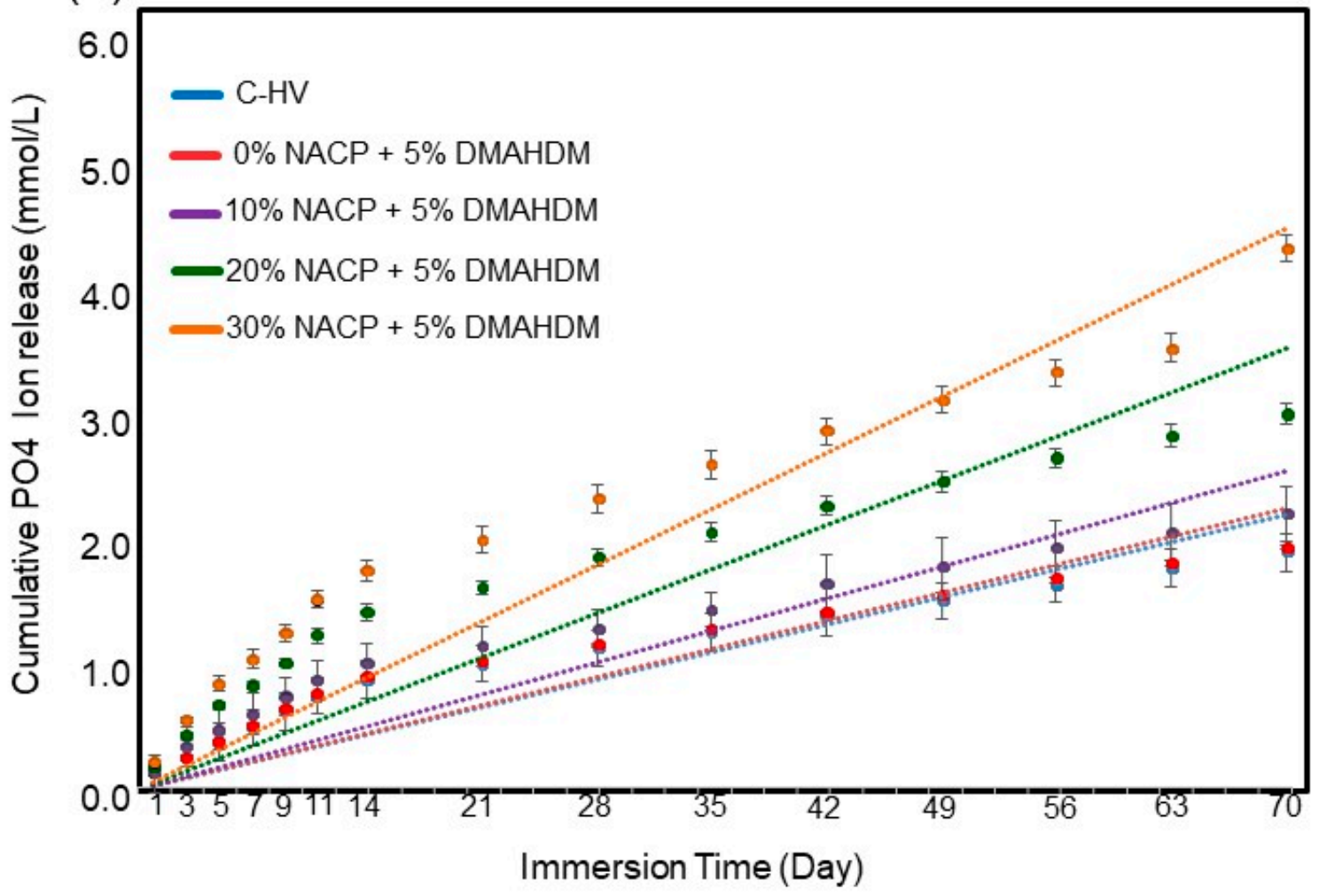

Figure 4. Cumulative initial ions release from sealants (Mean $\pm S D ; n=6$ ). In (A), Calcium (Ca) ion and in (B) Phosphate ions. The dots for each group show the exact data and the dotted line is its approximate linear trend for each formulation. 
The results of the three cycles of ion recharge and re-release are presented in Figure 5. The Ca ion re-releases after the first cycle were $0.46 \pm 0.03,0.73 \pm 0.03$, and $0.94 \pm 0.04$ for the experimental sealants with $10 \%, 20 \%$ and $30 \% \mathrm{NACP}$, respectively ( $p<0.05$ between the three groups). On the other hand, the $\mathrm{PO}_{4}$ ion re-release after the first cycle were $1.10 \pm 0.01,1.22 \pm 0.02$, and $1.25 \pm 0.03$ for the experimental sealants with $10 \%, 20 \%$ and $30 \%$ NACP, respectively $(p>0.05$ between the $20 \%$ and $30 \%$ $\mathrm{NACP}$ groups). All the experimental sealants showed good $\mathrm{Ca}$ and $\mathrm{PO}_{4}$ ion recharging abilities in the three cycles tested.
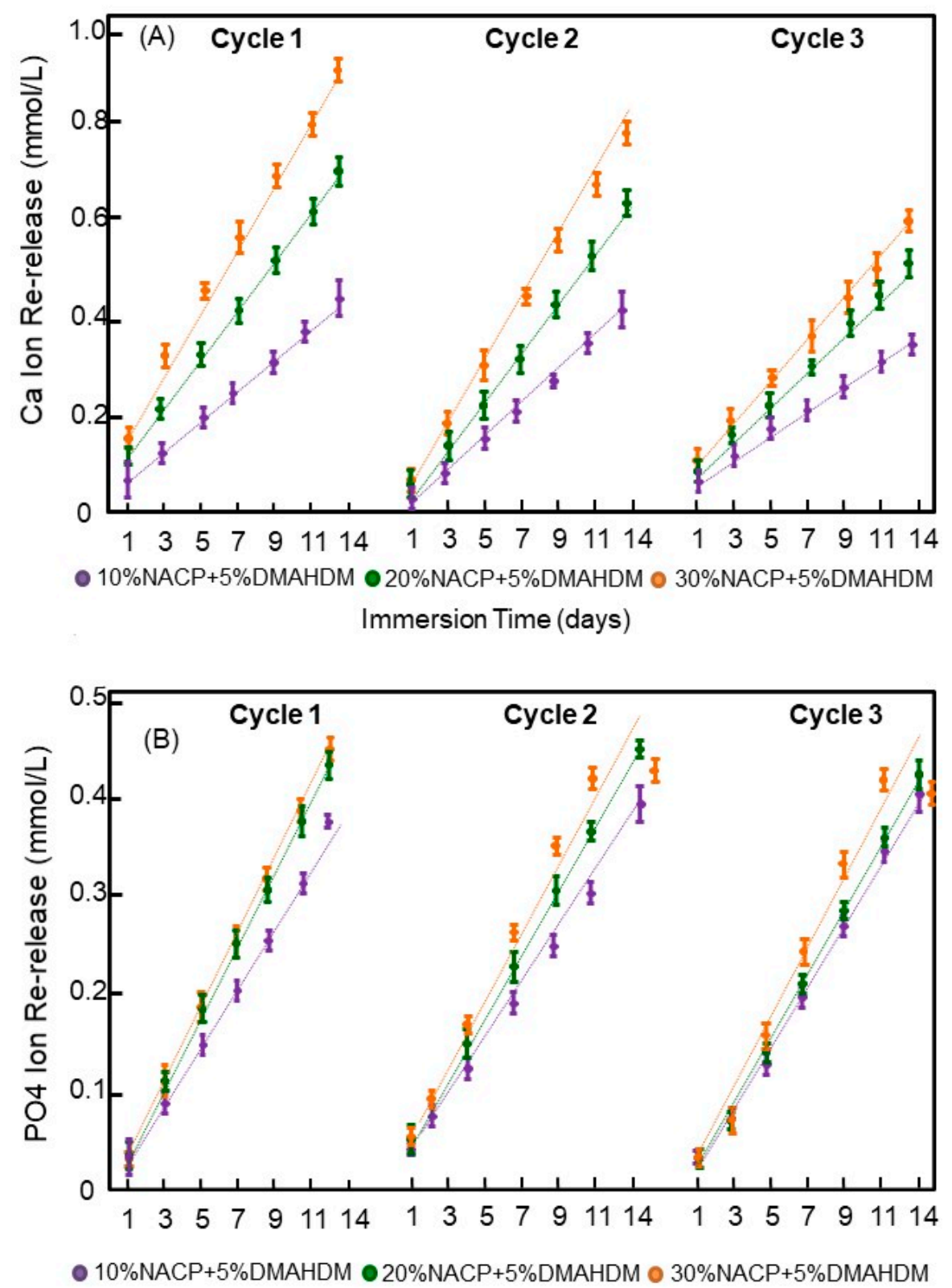

Figure 5. Cumulative ions re-release from the recharged resin dental sealants (Mean $\pm \mathrm{SD} ; n=3$ ) after three cycles of ions recharge and re-release. The dots for each group show the exact data and the dotted line is its approximate linear trend for each formulation. In (A), Calcium ion and in (B) Phosphate ions. There was no decrease in the ion re-release amounts with increasing the number of recharge and re-release cycles. 


\section{Discussion}

Recent studies have developed rechargeable NACP resin-based materials for long-term Ca and $\mathrm{PO}_{4}$ ion release to combat tooth decay [17,19], but the effects of NACP filler level on antibacterial sealant properties had not been reported. Developing a new dental material for sealant applications must meet the basic property requirements of clinicians. Thus, in the present study, an antibacterial and rechargeable $\mathrm{Ca}$ and $\mathrm{PO}_{4}$ releasing sealant was developed for the first time. The effects of NACP mass fraction on mechanical and physical performance and $\mathrm{Ca}$ and $\mathrm{PO}_{4}$ ions initial release and re-release were determined to allow the development of ideal formulation with bioavailable ions for potential enamel remineralization of occlusal pits and fissures.

In the case of the enlarged pit and fissure sealing, the mechanical properties of the material become more important since the material can be placed onto areas that encounter mechanical stresses during clenching [6]. In that situation, it appears clearly from the results that flowable resin composites have by far better flexural moduli than the pit and fissure sealants tested. Here, we assessed the flexural strength, flexural modulus and flow of different formulations and compared them to the commercial resin-based sealant and flowable composite that did not contain NACP. The percentage load of the glass filler ranged from $50 \%$ in $5 \%$ DMAHDM + $0 \%$ NACP sealant to $20 \%$ in $5 \%$ DMAHDM $+30 \%$ NACP formulation. Previous studies also revealed that the incorporation of a high content mass fraction of nanoparticles, such as $40 \%$ might have a negative impact on material properties [20,21]. Therefore, only three different mass fractions of NACP were used in this study: 5\% DMAHDM + $10 \%$ NACP, $5 \%$ DMAHDM + 20\% NACP, and 5\% DMAHDM + 30\% NACP. However, the results obtained in this study revealed a significant interference of the NACP at the $30 \%$ mass fraction with the flow of the experimental sealant. In deep fissures and grooves, the flow of the material is an important characteristic to help seal the total surface [4]. It is expected that the sealant's flow ability could be compromised when the experimental sealant incorporates the highest amount of NACP. Our findings suggest that the new formulation with $20 \%$ NACP did not negatively affect the mechanical and physical properties, while providing substantial $\mathrm{Ca}$ and $\mathrm{PO}_{4}$ ions to inhibit caries.

Adding different caries-preventive measures and strategies to the sealant may increase its effect on caries prevention [5]. In previous studies, antibacterial resins containing quaternary ammonium methacrylates with an alkyl chain length of 16 (DMAHDM) were synthesized and assessed with a higher antibacterial potency against oral bacteria as an outcome. The mechanism of positively charged quaternary amine disrupting the negatively charged bacterial membranes supported the decrease in bacterial coverage nearly $90 \%$ for resin formulations at 5\% DMAHDM [17,19]. The long-term antibacterial activity of DMAHDM was demonstrated by Zhang et al. [20] and attributed to the fact that the antibacterial monomer was copolymerized with the resin by forming a covalent bonding with the polymer network. Thus, the development of a resin-based dental sealant that also holds remineralizing properties could be essential to improve the function of the resin-based dental sealant on posterior teeth fissures and grooves for caries prevention.

Regarding recharge ability, this study builds upon the methodology provided by Zhang et al. [21]. Their report confirmed that the recharge of calcium and phosphate ions from resin-based formulations was achievable, while also establishing some of the variables important for ion release and recharge such as chemical composition of resin matrix and number of suitable cycles for recharge of the specimens. For the tested formulations, the $20 \%$ NACP sealant showed a release of $3.64 \pm 0.11 \mathrm{mmol} / \mathrm{L}(p<0.05)$ of $\mathrm{Ca}$ ions and $3.41 \pm 0.10 \mathrm{mmol} / \mathrm{L}$ of $\mathrm{PO}_{4}$ ions during the 70 -day period. The effect of the NACP percentage loading within the resin-based antibacterial formulation containing 5\% DMAHDM on the rate of $\mathrm{Ca}$ and $\mathrm{PO}_{4}$ is reported in Figure 4A,B. When comparing the $20 \%$ NACP formulation and $10 \%$ NACP formulation, an approximate three times increase in Ca and $\mathrm{PO}_{4}$ ions released was observed. However, as the NACP percentage load increased, the rate of diffusion of ions from the sealants increased approximately $5 \%$. It appears that an increase in the NACP concentration by a factor of 1.5 does not provide the same corresponding increase in $\mathrm{Ca}$ 
and $\mathrm{PO}_{4}$ ion concentration over 70 days, which makes the $20 \% \mathrm{NACP}$ formulations suitable for the proposed application.

Referring to previous studies from our group, this release concentration of $\mathrm{Ca}$ and $\mathrm{PO}_{4}$ ions was similar to release and recharge rates previously observed in a $30 \%$ NACP parental formulation with high inorganic filler content for reinforcement [17]. This variation could be attributed to the differences in the filler level in each formulation since in order for these ions to be available for remineralization, they must diffuse through the resin matrix, in this case, 50\% PEHB.

The chemical composition of the formulation has a unique role for rechargeability. Since one of our objectives in this study was to develop ion-rechargeable resin-based sealants, PEHB resin matrix was chosen. The PEHB resin had shown high ion-recharging abilities in previous reports [19,22,23]. In the present study, the sealant showed promising ion recharging abilities because of the great amount of re-released $\mathrm{Ca}$ and $\mathrm{PO}_{4}$ ions after each cycle of ion-recharge. This is likely due to the acidic adhesive monomer PMGDM [18], which consists of a large part of the parental resin matrix PEHB. The suggested recharge mechanism of NACP is based on the ability of PMGDM chelate with the recharging Ca ions during the recharging process, and release the ions when it is exposed to the acidic environment, such as $\mathrm{pH}$ 4. Further study is needed to investigate $\mathrm{Ca}$ and $\mathrm{P}$ ion recharge and re-release mechanisms in solutions that mimic the oral environment, such as artificial saliva.

\section{Materials and Methods}

\subsection{Development of Dental Resin Sealants}

The resin matrix consisted of $44.5 \%$ of pyromellitic glycerol dimethacrylate (PMGDM) (Hampford, Stratford, CT, USA), 39.5\% of ethoxylated bisphenol a dimethacrylate (EBPADMA) (Sigma-Aldrich, St. Louis, MO, USA), 10\% of 2-hydroxyethyl methacrylate (HEMA) (Esstech, Essington, PA, USA), and 5\% of bisphenol a glycidyl dimethacrylate (Esstech) [17]. 1\% of phenylbis (2,4,6-trimethylbenzoyl)-phosphine oxide (BAPO) (Sigma-Aldrich) was added as a photo-initiator. This resin matrix is referred to as PEHB. To formulate a sealant with antibacterial properties, dimethylaminohexadecyl methacrylate (DMAHDM) was synthesized via a modified Menschutkin reaction using a method as described previously [22].

NACP was synthesized by a spray-drying technique according to previous methodology [21]. Briefly, calcium carbonate and dicalcium phosphate were dissolved in acetic acid to produce $\mathrm{Ca}$ ions with a concentration of $8 \mathrm{mmol} / \mathrm{L}$ and $\mathrm{PO}_{4}$ ions with a concentration of $5.3 \mathrm{mmol} / \mathrm{L}$, then this solution was sprayed in a heated chamber using a spray-drying machine. An electrostatic precipitator was used to harvest the NACP with a particle size of average $\pm 116 \mathrm{~nm}$. The silanized barium boroaluminosilicate glass particles were added for reinforcement purposes and had an average size of $1.4 \mu \mathrm{m}$ (Caulk/Dentsply, Milford, DE, USA). The fillers were incorporated into the resin matrix at a filler level of $50 \%$. Two main types of resin-based materials were available as pit and fissure sealants: filled flowable composite and unfilled resin-based sealants, both were used as commercial controls in this study. Hence, the following six sealants were tested.

1. Commercial Low-viscosity Sealant control termed "C-LV." (FluroShield, Dentsply Caulk, Milford, DE, USA)".

2. Commercial High-viscosity Sealant/Flowable Composite control termed "C-HV." (Virtuoso, Den-Mat Holdings, Lompoc, CA, USA).

3. Experimental Sealant termed " $5 \%$ DMAHDM $+0 \%$ NACP" $(45 \%$ PEHB $+5 \%$ DMAHDM $+50 \%$ Glass $+0 \%$ NACP).

4. Experimental Sealant termed " $5 \%$ DMAHDM + 10\% NACP" ( $45 \%$ PEHB + 5\% DMAHDM + 40\% Glass + 10\% NACP).

5. Experimental Sealant termed "5\% DMAHDM + 20\% NACP" (45\% PEHB + 5\% DMAHDM + 30\% Glass + 20\% NACP). 
6. Experimental Sealant termed " $5 \%$ DMAHDM $+30 \%$ NACP" $(45 \%$ PEHB $+5 \%$ DMAHDM $+20 \%$ Glass $+30 \%$ NACP).

\subsection{Flexural Strength and Flexural Modulus}

Samples for flexural strength and flexural modulus testing were prepared using $2 \times 2 \times 25 \mathrm{~mm}$ stainless steel molds. Each paste was placed into the mold which was covered with Mylar strips and glass slides from both open sides of the mold then light-cured $\left(500 \mathrm{~mW} / \mathrm{cm}^{2}, 60 \mathrm{~s}\right.$, Triad 2000, Dentsply, York, PA, USA) for on each open side. Samples were stored at $37^{\circ} \mathrm{C}$ for $24 \mathrm{~h}$. Flexural strength and flexural modulus were measured using three-point flexure with a $10 \mathrm{~mm}$ span at a crosshead-speed of $1 \mathrm{~mm} / \mathrm{min}$ on a computer-controlled universal testing machine (MTS 5500R, Cary, NC, USA) [24].

Flexural strength $(\mathrm{F})$ was calculated by using the following formula:

$\mathrm{F}=(3 \mathrm{LS}) /\left(2 \mathrm{WH}^{2}\right)$, where $\mathrm{L}$ is the maximum load; $\mathrm{S}$ is the span; $\mathrm{W}$ is the width of the specimen and $\mathrm{H}$ is the height.

Flexural Modulus $(\mathrm{M})$ was determined as:

$\mathrm{M}=\left(\mathrm{LS}^{3} 3\right) /\left(4 \mathrm{WH}^{3} 3 \mathrm{~d}\right)$, where $\mathrm{L}$ is the maximum load; $\mathrm{S}$ is the span; $\mathrm{W}$ is the width of the specimen, $\mathrm{H}$ is the height of the specimen, and $\mathrm{d}$ is the defluxion corresponding to the load $\mathrm{L}$.

\subsection{Flow Analysis}

The recommendations of the ISO 6876/2012 and ANSI/ADA2000 standards were followed [25]. Briefly, two glass plates of $40 \mathrm{~mm} \times 40 \mathrm{~mm}$ and approximately $5 \mathrm{~mm}$ thickness were used. The weight of one glass plate was approximately $20 \mathrm{~g}$. The paste of each sealant was placed in the center of one of the glass plates using a graduated syringe. The amount of sealant was approximately $0.05 \mathrm{~mL}$. The second glass plate was placed on top of the sealant; then a $100 \mathrm{~g}$ weight was used to make a total weight of approximately $120 \mathrm{~g}$. After 10 minutes, the weight was removed, and the largest and smallest diameters of the discs formed by the compressed sealants were measured with the aid of a digital caliber (Mitutoyo MTI Corp., Huntersville, NC, USA) [26]. Six tests were done for each sealant.

\subsection{Measurement of Initial Calcium and Phosphate Ions Release from NACP}

Three specimens of approximately $2 \times 2 \times 12 \mathrm{~mm}$ were immersed in $50 \mathrm{~mL}$ of sodium chloride $(\mathrm{NaCl})$ solution $(133 \mathrm{mmol} / \mathrm{L})$. The $\mathrm{NaCl}$ solution was previously buffered to $\mathrm{pH} 4$ with $50 \mathrm{mmol} / \mathrm{L}$ of lactic acid to simulate a cariogenic low $\mathrm{pH}$ condition [27]. The specimen volume per solution ratio was almost $2.9 \mathrm{~mm}^{3} / \mathrm{mL}$ following previous study [22]. The tubes $(n=6)$ were kept in a $37^{\circ} \mathrm{C}$ incubator during the experiment. Aliquots were collected at 1, 3, 5, 7, 9, 11, 14, 21, 28, 35, 42, 49, 56, 63 and 70 days. The $\mathrm{Ca}$ and $\mathrm{PO}_{4}$ ions concentrations from collected aliquots were analyzed using SpectraMax ${ }^{\circledR}$ M Series Multi-Mode Microplate Reader from Molecular Devices [28]. The absorbance was measured using known standards and calibration curves. After each collection, the $\mathrm{NaCl}$ solution was replaced by a fresh solution. All the groups were tested for the initial $\mathrm{Ca}$ and $\mathrm{PO}_{4}$ ions release [29].

\subsection{Calcium and Phosphate Ions Recharge and Re-Release}

After the calcium and phosphate ions released for 70 days, the specimens were stored for almost 6 months before starting the ion recharging experiment to exhaust the ions in all the specimen and ensure there is no additional ion release. The $\mathrm{pH}$ of the immersion solutions was assessed by the same period of time. Then, these ion-exhausted specimens were used for the ion recharging experiment. The Ca ion recharging solution was made of $100 \mathrm{mmol} / \mathrm{L} \mathrm{CaCl}_{2}$ and $50 \mathrm{mmol} / \mathrm{L} \mathrm{HEPES} \mathrm{buffer} \mathrm{[18].}$ The $\mathrm{PO}_{4}$ ion recharge solution was made of $60 \mathrm{mmol} / \mathrm{L} \mathrm{KHPO}_{4}$ and $50 \mathrm{mmol} / \mathrm{L}$ HEPES buffer. Both solutions were adjusted to $\mathrm{pH} 7$ by the use of $1 \mathrm{~mol} / \mathrm{L} \mathrm{KOH} \mathrm{[19].} \mathrm{Three} \mathrm{specimens} \mathrm{of} \mathrm{approx.} 2 \times 2 \times$ $12 \mathrm{~mm}$ were immersed in $5 \mathrm{~mL}$ of the calcium ion or phosphate ion recharging solution and gently vortexed for 1 min using Analog Vortex Mixer, (Fisher Scientific, Waltham, MA, USA) to simulate the action of using mouthwash [30]. Specimens were immersed three times for 1 minute each time. This is for a total of $3 \mathrm{~min}$ of ion recharge. After that, the recharged specimens were immersed in a 
$50 \mathrm{~mL} \mathrm{NaCl}$ solution, which was adjusted to $\mathrm{pH} 4$ as described in Section 4.4. This immersion was to measure the $\mathrm{Ca}$ and $\mathrm{PO}_{4}$ ion re-release on day 1, 2, 3, 5, 9, 11 and 14 . After 14 days, the specimens were recharged again, and then the ion re-release was measured for 14 days at day 1, 2, 3, 5, 7, 9, 11 and 14 [31]. The same cycle or recharge and release were repeated for three times as described in Figure 1. The $\mathrm{Ca}$ and $\mathrm{PO}_{4}$ ion measurements were assessed in the same way as mentioned in Section 4.4.

\subsection{Statistical Analysis}

Kolmogorov-Smirnov test and Levene test were performed to confirm the normality and equal variance of data. The results of flexural strength, flexural modulus, flow and $\mathrm{Ca}$ and $\mathrm{PO}_{4}$ ion release and re-release were analyzed using one-way analysis of variance (ANOVA). Multiple comparisons between the different groups were conducted using Bonferroni's multiple comparison tests. All the statistical analyses were performed by SPSS 22.0 software (SPSS, Chicago, IL, USA) at an alpha of 0.05 .

\section{Conclusions}

The effects of different percentage loading of the remineralizing agent, NACP in new dental material formulations have been studied in a thorough and systematic approach. Considering the clinically relevant properties for dental sealants, the formulation containing $20 \%$ of NACP was selected as the optimal composition. The material flow was highly related to the mass fraction of the filler in the resin. At 20\% NACP, the PEHB-based resin sealant provides high levels of $\mathrm{Ca}$ and $\mathrm{PO}_{4}$ ions release and durable repeated recharge capability, with no negative effect on the mechanical and physical properties of the sealant. Therefore, this is a promising approach to provide long-term ion release to promote remineralization and inhibit dental caries in occlusal surfaces of teeth in children and adolescents.

Author Contributions: Conceptualization, H.H.K.X., and M.A.S.M.; Methodology, H.H.K.X. and M.A.S.M.; Investigation, M.S.I., F.D.A., Y.A.A.-D.; Writing-M.S.I. and M.A.S.M.; Writing-Review \& Editing, H.H.K.X.; Funding Acquisition, H.H.K.X., and M.A.S.M.; Resources, M.D.W., T.W.O.; Supervision, M.D.W. and T.W.O.; Project Administration, M.A.S.M. and M.D.W.

Funding: This study was supported by NIH R01DE17974 (HX) and a Seed Grant (HX, MM) from the University of Maryland School of Dentistry.

Acknowledgments: We thank Pei Feng, Associate Dean of Research, UMB School of Dentistry, and Nancy Lin, National Institute of Standards and Technology for comments that greatly improved the manuscript.

Conflicts of Interest: The authors declare no conflict of interest.

\section{References}

1. GBD 2015 Disease and Injury Incidence and Prevalence Collaborators. Global, regional, and national incidence, prevalence, and years lived with disability for 310 diseases and injuries, 1990-2015: A systematic analysis for the Global Burden of Disease Study 2015. Lancet 2017, 388, 1545-1602.

2. Benzian, H.; Hobdell, M.; Mackay, J. Putting teeth into chronic diseases. Lancet 2011, 377, 464. [CrossRef]

3. Skeie, M.S.; Klock, K.S. Dental caries prevention strategies among children and adolescents with immigrant-or low socioeconomic backgrounds- do they work? A systematic review. BMC Oral Health 2018, 18, 20. [CrossRef] [PubMed]

4. Ahovuo-Saloranta, A.; Forss, H.; Walsh, T.; Nordblad, A.; Mäkelä, M.; Worthington, H.V. Pit and fissure sealants for preventing dental decay in permanent teeth. Cochrane Database Syst. Rev. 2017, 7, 1-167. [CrossRef] [PubMed]

5. Beauchamp, J.; Caufield, P.W.; Crall, J.J.; Donly, K.; Feigal, R.; Gooch, B.; Ismail, A.; Kohn, W.; Siegal, M.; Simonsen, R. Evidence-based clinical recommendations for the use of pit-and-fissure sealants: A report of the American Dental Association Council on Scientific Affairs. J. Am. Dent. Assoc. 2008, 139, 257-268. [CrossRef] [PubMed]

6. Poulsen, S.; Beiruti, N.; Sadat, N. A comparison of retention and the effect on caries of fissure sealing with a glass-ionomer and a resin-based sealant. Community Dent. Oral Epidemiol. 2001, 29, 298-301. [CrossRef] [PubMed] 
7. Cury, J.A.; Tenuta, L.M.A. Enamel remineralization: Controlling the caries disease or treating early caries lesions? Braz. Oral Res. 2009, 23, 23-30. [CrossRef] [PubMed]

8. Tenuta, L.M.; Del Bel Cury, A.A.; Bortolin, M.C.; Vogel, G.L.; Cury, J.A. Ca, Pi, and F in the fluid of biofilm formed under sucrose. J. Dent. Res. 2006, 85, 834-838. [CrossRef] [PubMed]

9. Melo, M.A.; Orrego, S.; Weir, M.D.; Xu, H.H.; Arola, D.D. Designing multi-agent dental materials for enhanced resistance to biofilm damage at the bonded interface. ACS Appl. Mater. Interfaces 2016, 8, 11779-11787. [CrossRef] [PubMed]

10. Feng, X.; Zhang, N.; Xu, H.H.; Weir, M.; Melo, M.A.; Bai, Y.; Zhang, K. Novel orthodontic cement containing dimethylaminohexadecyl methacrylate with strong antibacterial capability. Dent. Mater. J. 2017, 36, 669-676. [CrossRef] [PubMed]

11. Weir, M.D.; Chow, L.C.; Xu, H.H.K. Remineralization of demineralized enamel via calcium phosphate nanocomposite. J. Dent. Res. 2012, 91, 979-984. [CrossRef] [PubMed]

12. Melo, M.A.S.; Weir, M.D.; Rodrigues, L.K.A.; Xu, H.H.K. Novel calcium phosphate nanocomposite with caries-inhibition in a human in situ model. Dent. Mater. 2013, 29, 231-240. [CrossRef] [PubMed]

13. Melo, M.A.S.; Guedes, S.F.F.; Xu, H.H.K.; Rodrigues, L.K.A. Nanotechnology-based restorative materials for dental caries management. Trends Biotechnol. 2013, 31, 459-467. [CrossRef] [PubMed]

14. Cheng, L.; Zhang, K.; Weir, M.D.; Melo, M.A.; Zhou, X.; Xu, H.H. Nanotechnology strategies for antibacterial and remineralizing composites and adhesives to tackle dental caries. Nanomedicine 2015, 10, 627-641. [CrossRef] [PubMed]

15. Chole, D.; Lokhande, P.; Shashank, K.; Bakle, S.; Devagirkar, A.; Dhore, P. Comparative Evaluation of the Fluoride Release and Recharge through Four Different Types of Pit and Fissure Sealants: An In Vitro Study. Int. J. Adv. Heal Sci. 2015, 2, 1-6.

16. Melo, M.A.S.; Powers, M.; Passos, V.F.; Weir, M.D.; Xu, H.H. Ph-activated nano-amorphous calcium phosphate-based cement to reduce dental enamel demineralization. Artif. Cells Nanomed. Biotechnol. 2017, 45, 1778-1785. [CrossRef] [PubMed]

17. Al-Dulaijan, Y.A.; Cheng, L.; Weir, M.D.; Melo, M.A.S.; Liu, H.; Oates, T.W.; Wang, L.; Xu, H.H.K. Novel rechargeable calcium phosphate nanocomposite with antibacterial activity to suppress biofilm acids and dental caries. J. Dent. 2018, 72, 44-52. [CrossRef] [PubMed]

18. Melo, M.A.; Cheng, L.; Weir, M.D.; Hsia, R.C.; Rodrigues, L.K.; Xu, H.H. Novel dental adhesive containing antibacterial agents and calcium phosphate nanoparticles. J. Biomed. Mater. Res. B Appl. Biomater. 2013, 101, 620-629. [CrossRef] [PubMed]

19. Li, F.; Weir, M.D.; Chen, J.; Xu, H.H.K. Effect of charge density of bonding agent containing a new quaternary ammonium methacrylate on antibacterial and bonding properties. Dent. Mater. 2014, 30, 433-441. [CrossRef] [PubMed]

20. Zhang, K.; Cheng, L.; Wu, E.J.; Weir, M.D.; Bai, Y.; Xu, H.H. Effect of water-ageing on dentine bond strength and anti-biofilm activity of bonding agent containing new monomer dimethylaminododecyl methacrylate. J. Dent. 2013, 41, 504-513. [CrossRef] [PubMed]

21. Zhang, L.; Weir, M.D.; Chow, L.C.; Antonucci, J.M.; Chen, J.; Xu, H.H.K. Novel rechargeable calcium phosphate dental nanocomposite. Dent. Mater. 2016, 32, 285-293. [CrossRef] [PubMed]

22. Wu, J.; Zhou, H.; Weir, M.D.; Melo, M.A.; Levine, E.D.; Xu, H.H. Effect of the dimethylaminohexadecyl methacrylate mass fraction on fracture toughness and antibacterial properties of CaP nanocomposite. J. Dent. 2015, 43, 1539-1546. [CrossRef] [PubMed]

23. Zhang, N.; Melo, M.A.; Chen, C.; Liu, J.; Weir, M.D.; Bai, Y.; Xu, H.H. Development of a multifunctional adhesive system for prevention of root caries and secondary caries. Dent. Mater. 2015, 31, 1119-1131. [CrossRef] [PubMed]

24. Xie, X.J.; Xing, D.; Wang, L.; Zhou, H.; Weir, M.D.; Bai, Y.X.; Xu, H.H. Novel rechargeable calcium phosphate nanoparticle-containing orthodontic cement. Int. J. Oral Sci. 2017, 9, 24-32. [CrossRef] [PubMed]

25. Melo, M.A.; Wu, J.; Weir, M.D.; Xu, H.H. Novel antibacterial orthodontic cement containing quaternary ammonium monomer dimethylaminododecyl methacrylate. J. Dent. 2014, 42, 1193-1201. [CrossRef] [PubMed]

26. Zhang, N.; Melo, M.A.; Antonucci, J.; Lin, N.; Lin-Gibson, S.; Bai, Y.; Xu, H.H. Novel dental cement to combat biofilms and reduce acids for orthodontic applications to avoid enamel demineralization. Materials 2016, 9, 413. [CrossRef] [PubMed] 
27. Zhang, N.; Weir, M.D.; Chen, C.; Melo, M.A.; Bai, Y.; Xu, H.H. Orthodontic cement with protein-repellent and antibacterial properties and the release of calcium and phosphate ions. J. Dent. 2016, 50, 51-59. [CrossRef] [PubMed]

28. ISO 6876:2012. Dentistry-Root Canal Sealing Materials; International Organization for Standardization: Geneva, Switzerland, 2012.

29. Xie, X.; Wang, L.; Xing, D.; Arola, D.D.; Weir, M.D.; Bai, Y.; Xu, H.H. Protein-repellent and antibacterial functions of a calcium phosphate rechargeable nanocomposite. J. Dent. 2016, 52, 15-22. [CrossRef] [PubMed]

30. Melo, M.A.; Cheng, L.; Zhang, K.; Weir, M.D.; Rodrigues, L.K.; Xu, H.H. Novel dental adhesives containing nanoparticles of silver and amorphous calcium phosphate. Dent. Mater. 2013, 29, 199-210. [CrossRef] [PubMed]

31. Zhang, L.; Weir, M.D.; Chow, L.C.; Reynolds, M.A.; Xu, H.H.K. Rechargeable calcium phosphate orthodontic cement with sustained ion release and re-release. Sci. Rep. 2016, 6, 36476. [CrossRef] [PubMed]

(C) 2018 by the authors. Licensee MDPI, Basel, Switzerland. This article is an open access article distributed under the terms and conditions of the Creative Commons Attribution (CC BY) license (http://creativecommons.org/licenses/by/4.0/). 